\title{
Structure Selection in a Two-echelon Supply Chain Under Different Channel Powers
}

\author{
Dapeng Yang ${ }^{1, a^{*}}$ Xiaofeng Gong ${ }^{2, b}$ \\ ${ }^{1}$ College of Information and Management Science, Henan Agricultural University, Zhengzhou, China \\ ${ }^{2}$ Business School, Chengdu University of Technology, Chengdu, China \\ aemail:yangdapeng081219@126.com bemail:gongxiaofengmail@126.com
}

Keywords: Channel selection; Pricing; Substitutability; Power structure.

\begin{abstract}
Channel selection for two substitutable products in a supply chain with one common retailer and two competitive manufacturers are considered in this paper. The purpose of this paper is to analyze the effects of the channel members' different power structures competitive strategies. By comparing different channels, we determined the best sale channel and market strategy for the manufacturer, the retailer and the consumer.
\end{abstract}

\section{Introduction}

Consider two competing manufacturers choose the common retailer to sell their products.Both the manufacturers and the retailer have powers. For example, as a powerful manufacturer, Microsoft and Intel always have more dominant right than their bottom strands. On the other hand, some retailers are more powerful in cases, such as Carrefour and Wal-Mart, they are playing a more significant role than their upstream firm in some market chains, they reduce the retail price of the product to ensure its profits. However, with the competition in the market becoming white-hot, the ideas like "whether manufacturer is leading or retail terminal for the king" are difficult to adapt to the objective environment, so the power balance in supply chain structure has been developed. But can be the leader of the structure will bring excess profits than the other supply chain members?

There is a stream of literature that studies the impacts of power structure on various aspects of channel management. Choi (1991) considers three possible channel configurations with power balanced suppliers: Manufacturer Stackelberg (MS), Retailer Stackelberg (RS), and Vertical Nash (VN). Ertek(2002)investigates the effect of power structure on price, profits and sensitivity of the market price in a two-stage supply chain. The research analyses the case where the buyer has dominant bargaining power and the case where the supplier has dominant bargaining power. Raju(2005) study channel coordination in the context of a retailer Stackelberg and their finding shows that a channel can be coordinated through either quantity discounts or a menu of two-part tariffs to the manufacturer's benefit. Using a similar power structure setting, Kolay(2013)study channel coordination and contract design when an upstream firm sells its products in a downstream market, and their finding indicates that quantity discounts and two-part tariffs can be mechanisms for channel coordination under some conditions. From Supplier-Stackelberg, Retailer-Stackelberg, and Nash game theoretical perspectives, Cai(2009)examines the impact of price discounts and price schemes on the dual-channel supply chain competition. Using a similar game-theory-based framework, Zhang (2012) study the effect of products' substitutability and channel status on pricing decision under different power structures in two dual exclusive channels and their finding indicates that the Vertical Nash game is equilibrium for the supply chain members and no power structure is always the best for the entire supply chain. Xia (2011) studied competition between two coexisting suppliers in a two-echelon supply chain, where each supplier offers one type of the two substitutable products to multiple buyers. 


\section{Problem description}

The purpose of this paper is to study the impact of channel power on performance in reality. This sequencing of decisions is a direct reflection of the relative difference in channel power among the supply chain agents. Accordingly, for the two-supplier-one-retailer supply chain eight relative power configurations are proposed, as shown in Fig.1.If M1 holds more power than M2 in the supply chain, this is represented by M1 $\rightarrow$ M2 in Fig.1.That is, M2 makes decisions only after observing the decisions of M1.M1 $\leftrightarrow \mathrm{M} 2$ indicates that M1 and M2 have equal decision-making power, and thus, M1 and M2 make their choices simultaneously. The eight distinct structures are marked (S1) through (S8).
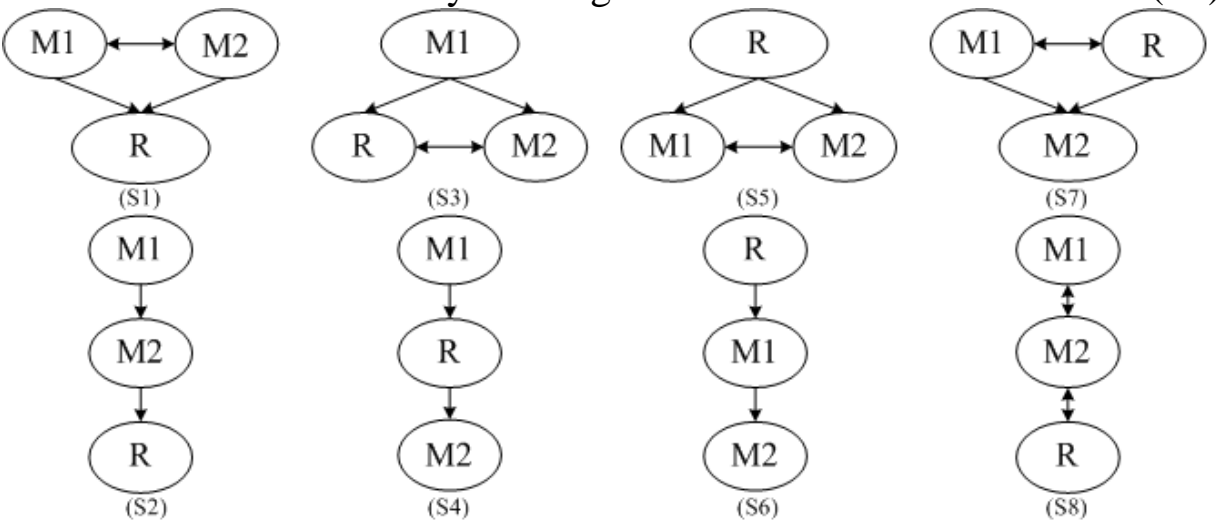

Fig. 1 Supply chain decision structures

Following signs need to be defined during modeling in this paper:

$p_{i}$ : the unit retail price of product $(i=1,2)$, where $p_{1}$ represents the product price of manufacturer ${ }^{M_{1}}$, and ${ }^{p_{2}}$ represents the product price of manufacturer ${ }^{M_{2}}$.

$w_{i}$ : the unit wholesale price of product $(i=1,2)$, where ${ }^{w_{1}}$ represents the wholesale price of manufacturer ${ }^{M_{1}}$, and ${ }^{w_{2}}$ represents the wholesale price of manufacturer ${ }^{M_{2}}$.

$D_{i}$ : the demand of product $(i=1,2)$, where ${ }^{D_{1}}$ represents the product demand of manufacturer $M_{1}$, and ${ }^{D_{2}}$ represents the product demand of manufacturer $M_{2}$.

$\theta$ : the products substitutability,where $\theta=0$, the products are purely monopolistic and where $\theta$ goes to 1 , the products converge to purely substitutable.

$a_{i}$ :is the base demand of product $i$.

$\Pi_{m i}$ : the profits in traditional channels for manufacture $i$.

$\Pi_{r}$ :the profits for the retailer.

For simplicity, we assume that the manufacturer's production costs and online channels operating cost is zero.This paper adopted the consumer utility function of Ingene (2007) Cai(2010),Liu(2014), established the demand function according to the consumer utility function:

$$
U \equiv \sum_{i=1,2}^{n}\left(a_{i} D_{i}-\frac{D_{i}^{2}}{2}\right)-\theta D_{1} D_{2}-\sum_{i=1,2} p_{i} D_{i}
$$

can get the demand functions respectively for manufacturer $M_{1}$ and manufacturer $M_{2}$ :

$$
D_{i}=\frac{a_{i}-\theta a_{3-i}-p_{i}+\theta p_{3-i}}{1-\theta^{2}}(i=1,2)
$$

Then, the profit functions of manufacturers and their online channels and retailer can be expressed as:

$$
\Pi_{m i}=w_{i} D_{i}, \quad \Pi_{r}=\sum_{i=1}^{2}\left(p_{i}-w_{i}\right) D_{i}
$$




\section{Comparisons and managerial implications}

In this subsection, we consider the special case that the parameters in eight pricing models established above are all symmetric, that is, $a_{1}=a_{2}=a$. The following theorem summarizes the results when two substitutable products are symmetric.

Theorem 1. When two substitutable products have symmetric parameters, the equilibrium solutions for the eight pricing models can be summarized as shown in Tables 1 and 2, where $a_{1}=a_{2}=a$.

Tables 1 and 2 indicate that the two substitutable products achieve equal wholesale prices and equal retail prices in the S1 to S8 models. From this, the following Insight 1 can be obtained.

Table 1 Equilibrium solutions in S1 to S4 models when two substitutable products are symmetric

\begin{tabular}{ccccc}
\hline Price & $\mathrm{S} 1$ & $\mathrm{~S} 2$ & $\mathrm{~S} 3$ & $\mathrm{~S} 4$ \\
\hline$w_{1}^{*}$ & $\frac{a(1-\theta)}{2-\theta}$ & $\frac{(1-\theta)}{2(2-\theta)}$ & $\frac{a\left(2-\theta-\theta^{2}\right)}{2\left(2-\theta^{2}\right)}$ & $\frac{a\left(2-\theta-\theta^{2}\right)}{2\left(2-\theta^{2}\right)}$ \\
$w_{2}^{*}$ & $\frac{a(1-\theta)}{2-\theta}$ & $\frac{(1-\theta)}{2(2-\theta)}$ & $\frac{a\left(4-2 \theta-3 \theta^{2}+\theta^{3}\right)}{8\left(2-\theta^{2}\right)}$ & $\frac{a\left(4-2 \theta-3 \theta^{2}+\theta^{3}\right)}{4\left(2-\theta^{2}\right)}$ \\
$p_{1}^{*}$ & $\frac{3 a-2 a \theta}{4-2 \theta}$ & $\frac{3 a-2 a \theta}{4-2 \theta}$ & $\frac{a\left(6-\theta-3 \theta^{2}\right)}{4\left(2-\theta^{2}\right)}$ & $\frac{a\left(6-\theta-3 \theta^{2}\right)}{4\left(2-\theta^{2}\right)}$ \\
$p_{2}^{*}$ & $\frac{3 a-2 a \theta}{4-2 \theta}$ & $\frac{3 a-2 a \theta}{4-2 \theta}$ & $\frac{a\left(12-2 \theta-7 \theta^{2}+\theta^{3}\right)}{8\left(2-\theta^{2}\right)}$ & $\frac{a\left(12-2 \theta-7 \theta^{2}+\theta^{3}\right)}{8\left(2-\theta^{2}\right)}$ \\
\hline
\end{tabular}

Table 2 Equilibrium solutions in S5 to S8 models when two substitutable products are symmetric

$\begin{array}{ccccc}\text { Price } & \text { S5 } & \text { S6 } & \text { S7 } & \text { S8 } \\ w_{1}^{*} & \frac{a\left(2-\theta-\theta^{2}\right)}{8-6 \theta^{2}} & \frac{a\left(2-\theta-\theta^{2}\right)}{2-\theta^{2}} & \frac{a}{2} & \frac{a(1-\theta)}{3-\theta} \\ w_{2}^{*} & \frac{a\left(2-\theta-2 \theta^{2}+\theta^{3}\right)}{8-6 \theta^{2}} & \frac{a\left(1-\theta^{2}\right)}{2\left(2-\theta^{2}\right)} & a-\frac{a \theta}{2} & \frac{a(1-\theta)}{3-\theta} \\ p_{1}^{*} & \frac{a\left(6-\theta-4 \theta^{2}\right)}{8-6 \theta^{2}} & \frac{a\left(4-\theta-2 \theta^{2}\right)}{2\left(2-\theta^{2}\right)} & \frac{3 a}{4} & \frac{a(2-\theta)}{3-\theta} \\ p_{2}^{*} & \frac{a\left(6-\theta-5 \theta^{2}+\theta^{3}\right)}{8-6 \theta^{2}} & \frac{3 a-2 a \theta^{2}}{4-2 \theta^{2}} & a-\frac{a \theta}{4} & \frac{a(2-\theta)}{3-\theta}\end{array}$

Insight 1 The two substitutable products achieve equal wholesale prices and equal retail prices in S1, S2, and S8 models. This means that the two manufacturers' different competitive strategies and the differences of channel powers between the two echelons do not make the two substitutable products achieve different wholesale prices and different retail prices in S1, S2, and S8 models.

Insight 2 When $\theta \in(0,1)$ the comparison of $\mathrm{M} 1$ profit as the follows: $\mathrm{S} 3>\mathrm{S} 2=\mathrm{S} 4>\mathrm{S} 1>\mathrm{S} 8>\mathrm{S} 5>\mathrm{S} 6>\mathrm{S} 7=0$.

As illustrated in Figs.2, due to the strong manufacturer has equal power with the retailer in the market, we can find in S7 that the retailer will select the weak manufacturer to ensure its leadership, so the strong manufacturers' profit is zero. And when the dominance manufacturer as the market leader, it can gain more profit no matter what is the relationship between its rival and the downstream retailer. 


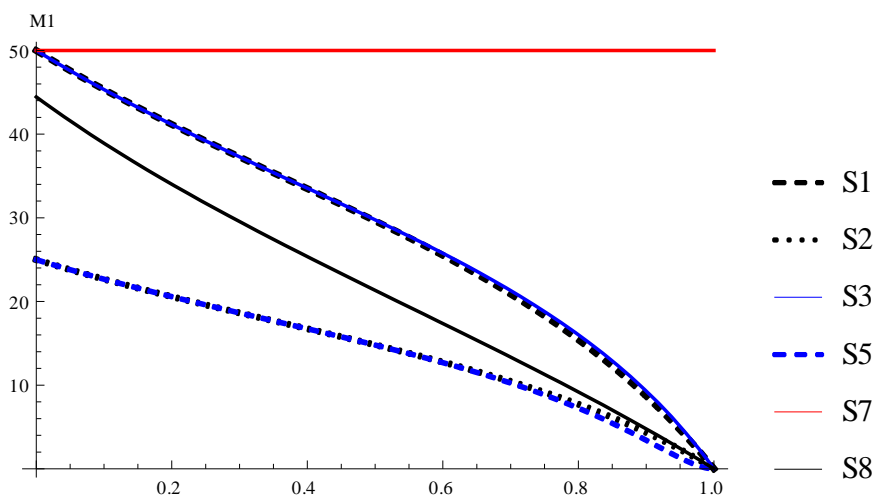

Fig. 2 The comparison of M1 profit when $a=20$

Insight 3 When $\theta \in(0,1)$ the comparison of $\mathrm{M} 2$ profit as the following: table 3 .

From table 3 and Figs.3, we can see in S3 manufacturer M2's profit is zero. The retailer has equal power with the weakness manufacturer M2, but the retailer afraid once its relationship with the weakness manufacturer become badly, it will only purchase products from M1.For the weakness manufacturer, it can low his market status to collaborate with the retailer to get more profits.

Table 3 Comparison of M2 profit in S1 to S8 models when two substitutable products are symmetric

\begin{tabular}{ll}
\hline \multicolumn{1}{c}{$\theta$} & profit comparisons of $\mathrm{M} 2$ \\
\hline$(0.883,1)$ & $\mathrm{S} 7>\mathrm{S} 4>\mathrm{S} 6>\mathrm{S} 1>\mathrm{S} 2>\mathrm{S} 8>\mathrm{S} 5>\mathrm{S} 3$ \\
$(0.796,0.883)$ & $\mathrm{S} 7>\mathrm{S} 4>\mathrm{S} 1>\mathrm{S} 6>\mathrm{S} 2>\mathrm{S} 8>\mathrm{S} 5>\mathrm{S} 3$ \\
$(0.745,0.796)$ & $\mathrm{S} 7>\mathrm{S} 4>\mathrm{S} 1>\mathrm{S} 6>\mathrm{S} 8>\mathrm{S} 2>\mathrm{S} 5>\mathrm{S} 3$ \\
$(0.696,0.745)$ & $\mathrm{S} 4>\mathrm{S} 7>\mathrm{S} 1>\mathrm{S} 6>\mathrm{S} 8>\mathrm{S} 2>\mathrm{S} 5>\mathrm{S} 3$ \\
$(0.652,0.696)$ & $\mathrm{S} 4>\mathrm{S} 7>\mathrm{S} 1>\mathrm{S} 8>\mathrm{S} 6>\mathrm{S} 2>\mathrm{S} 5>\mathrm{S} 3$ \\
$(0.414,0.652)$ & $\mathrm{S} 4>\mathrm{S} 1>\mathrm{S} 7>\mathrm{S} 8>\mathrm{S} 6>\mathrm{S} 2>\mathrm{S} 5>\mathrm{S} 3$ \\
$(0,0.414)$ & $\mathrm{S} 4>\mathrm{S} 1>\mathrm{S} 8>\mathrm{S} 7>\mathrm{S} 6>\mathrm{S} 2>\mathrm{S} 5>\mathrm{S} 3$ \\
\hline
\end{tabular}

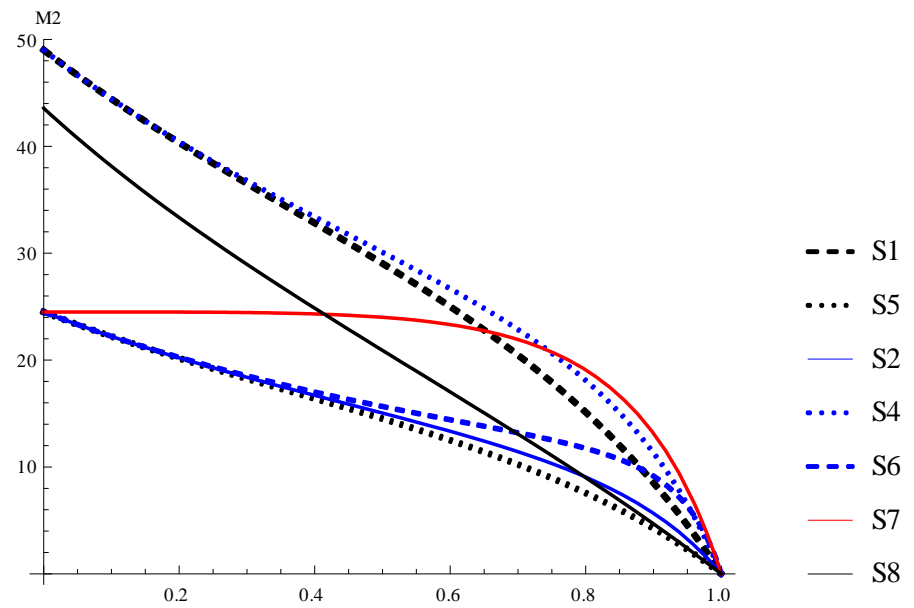

Fig. 3 The comparison of M2 profit when $a=20$

Insight 4. When $\theta \in(0,1)$ the comparison of retailer profit as the following: table 4 .

From table 4 and Figs. 4, we know when the retailer as the leader in the supply, it can gain maximum profit among the eight supply chain structures when the two manufacturers have equal power.

Table 4 Comparison of retailer profit in S1 to S8 models when two substitutable products are symmetric

\begin{tabular}{cc}
\hline$\theta$ & profit comparisons of $\mathrm{R}$ \\
\hline$(0,0.47)$ & $\mathrm{S} 5>\mathrm{S} 6>\mathrm{S} 8>\mathrm{S} 2>\mathrm{S} 1>\mathrm{S} 7>\mathrm{S} 4>\mathrm{S} 3$ \\
$(0.47,1)$ & $\mathrm{S} 5>\mathrm{S} 8>\mathrm{S} 6>\mathrm{S} 2>\mathrm{S} 1>\mathrm{S} 7>\mathrm{S} 4>\mathrm{S} 3$ \\
\hline
\end{tabular}




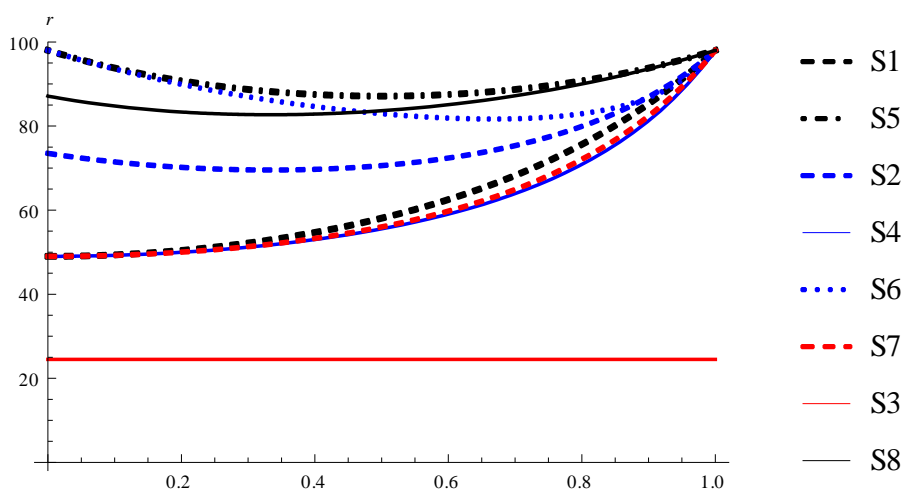

Fig. 4 The comparison of retailer profit when $a=20$

Insight 5. When $\theta \in(0,1)$ the comparison of consumer utility is: $\mathrm{S} 8>\mathrm{S} 1=\mathrm{S} 5>\mathrm{S} 2>\mathrm{S} 6>\mathrm{S} 7>\mathrm{S} 3=\mathrm{S} 4$.

As illustrated in Figs. 5, an increase in parameter $\theta$ increases the optimal consumer utility in S1, S2, S5, S6, and S7and S8.And in S8 models consumer can get best utility when the manufacturers and retailer has equal power in the market.

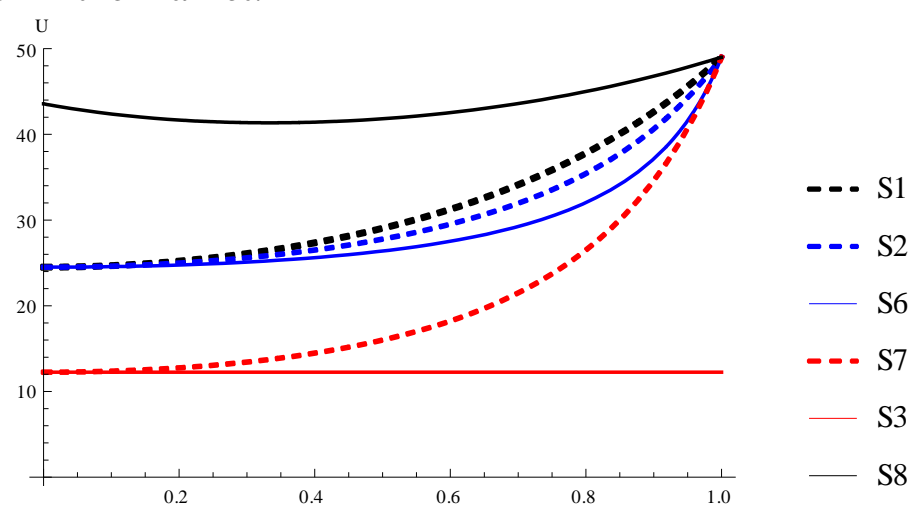

Fig. 5 The comparison of consumer profit when $a=20$

\section{Summary}

Similar to any other model previously published in the literature, the present model is also based on some assumptions. Thus, several extensions to the analysis in this paper are possible. First, as opposed to the risk neutral supply chain members considered in this paper, one could study the case where the supply chain members with different attitudes towards risk could also examine the influence of their attitudes towards risk on individual profits and the profit of the whole supply chain. Second, our analysis reveals that certain structures which perform well under linear demand could lead to rather poor profitability if demand is nonlinear. Moreover, in practice, customer demand is likely to be uncertain, while our analysis relies on deterministic demand forms. As a consequence, our findings are not likely to hold in environments that are characterized by high demand uncertainty.

\section{Acknowledgement}

In this paper, the research was sponsored by the Soft Science Foundation of Henan Province (Project No. 142400410044).

\section{References}

[1] Choi SC. Price competition in a channel structure with a common retailer.Marketing Science 1991;10(4):2 71-96. 
[2] Ertek G, Griffin PM. Supplier- and buyer-driven channels in a two-stage supply chain. IIE Transactions 2002;34(8):691-700.

[3] Raju J, Zhang ZJ. Channel coordination in the presence of a dominant retailer. Marketing Science 2005;24(2):254-62.

[4] Kolay S, Shaffer G. Contract design with a dominant retailer and a competitive fringe. Management Science 2013;59(9):2111-6.

[5] Cai GG, Zhang ZG, Zhang M. Game theoretical perspectives on dual-channel supply chain competition with price discounts and pricing schemes. International Journal of Production Economics 2009;117(1):80-96.

[6] Zhang R, Liu B, Wang W. Pricing decisions in a dual channels system with different power structures. Economic Modelling 2012;29(2):523-33.

[7] Cai G. Channel selection and coordination in dual-channel supply chains. Journal of Retailing 2010;86(1):22-36.

[8] Liu B, Cai G G, Tsay A A. Advertising in asymmetric competing supply chains [J]. Production and Operations Management, 2014, 23(11): 1845-1858.

[9] Xia Y. Competitive strategies and market segmentation for suppliers with substitutable products [J]. European Journal of Operational Research, 2011, 210(2): 194-203.

[10] Ingene, C., M. Parry. 2007. Bilateral monopoly, identical competitors/distributors, and game theoretic analyses of distribution channels. J. Acad. Mark. Sci. 35(4):586-602. 